\title{
Emerging trends in invasive and noninvasive isolates of Streptococcus agalactiae in a Latin American hospital: a 17-year study
}

\author{
Maria del Pilar Crespo-Ortiz ${ }^{1,2^{*}}$, Claudia Rocio Castañeda-Ramirez ${ }^{3,4}$, Monica Recalde-Bolaños $^{3}$
} and Juan Diego Vélez-Londoño ${ }^{3}$

\begin{abstract}
Background: Streptococcus agalactiae or group B Streptococcus (GBS) has been recognized as a lethal pathogen in neonates worldwide. S. agalactiae infections also severely affect pregnant women and immunosuppressed adults with substantial attributable morbidity and mortality. However, in Latin America, studies on the epidemiology and behaviour of $S$. agalactiae infections remain limited.

Methods: To better understand the behaviour of S. agalactiae infections in our region, we conducted a retrospective study to phenotypically describe $S$. agalactiae isolates collected in one of the largest hospitals in Colombia at two time periods: 1994-2001 and 2004-2012. The isolates were identified by biochemical analysis and tested for antimicrobial susceptibility.

Results: In 1994-2001 a total of 201 S. agalactiae isolates were found in urine 38.3\%, vaginal exudates 27.8\%, soft tissue $12.9 \%$, and blood $8.5 \%$. Susceptibility to ampicillin or penicillin was $94 \%$ whereas resistance to erythromycin and clindamycin were $2.8 \%$ and $5.2 \%$ respectively. In total 46 culture-positive cases of invasive infections were reported, 11 (24\%) in neonates and 35 (76\%) in adults. In 2004-2012 a total of 671 isolates were found in urine $47.8 \%$, vaginal exudates $32.6 \%$, soft tissue $2.7 \%$ and blood $9 \%$. Susceptibility rates to ampicillin and penicillin were $98 \%$ whereas resistance to erythromycin and clindamycin were $12.5 \%$ and $9.4 \%$. A total of 95 severe infections were reported: 12 (12.6\%) were in neonates, 5 (5.3\%) in children and 78 (82.1\%) in adults. Over the 17-year study period the averaged prevalence of invasive S. agalactiae isolates was $17.4 \%$. The estimated incidence for neonatal infections was 1.34 per 1000 livebirths $(0.99 \times 1000$ livebirths for early- onset disease and $0.35 \times 1000$ livebirths for late- onset disease) whereas for non-pregnant adults the estimated incidence was $0.75 \times 1000$ admissions.

Conclusions: A remarkable increase in bloodstream infections in immunosuppressed adults and a shift to early neonatal S. agalactiae infections were seen over time. We also found an increase in S. agalactiae resistance to erythromycin and clindamycin during the study period, and the emergence of penicillin-nonsusceptible isolates. Our findings are consistent with the global trends described elsewhere, reinforcing the need for S. agalactiae control measures in our region.
\end{abstract}

Keywords: Neonatal infections, Immunosuppression, Bacteremia, Streptococcus agalactiae, Group B Streptococcus

\footnotetext{
* Correspondence: mpcrespo@usc.edu.co

'Department of Biomedical Sciences, Santiago de Cali University, Cali, Colombia

${ }^{2}$ Department of Microbiology, University of Valle, Cali, Colombia

Full list of author information is available at the end of the article
} 


\section{Background}

Streptococcus agalactiae (Group B Streptococcus, GBS) is a colonizing bacterium in the gastrointestinal and genitourinary tracts of healthy adults, particularly in women [1-3]. Since 1970, S. agalactiae has been considered a very significant cause of severe neonatal infections with high morbidity and mortality. It also affects pregnant women, non-pregnant adults with underlying conditions and the elderly [4]. Maternal S. agalactiae colonization has been associated with early-onset neonatal septicemia ( $<7$ days of age) and meningitis with mortality rates up to $60 \%$ [5]. The highest rates of early neonatal infection occur in premature and low-birth-weight infants due to their immature immune systems. By contrast, late-onset infections ( $>7$ days of age) have been associated with $S$. agalactiae virulence, although less lethal, these infections are considered nosocomial and may lead to neurologic sequels in 30\% of survivors [6,7]. After 1990, in developed countries $S$. agalactiae screening and risk-based intrapartum chemoprophylaxis significantly reduced mortality to $5 \%$ [8]. However twenty years later, regardless a change in the epidemiology, $S$. agalactiae is still an important cause of severe infections. Intrapartum chemoprophylaxis has reduced the early-onset disease in neonates $[9,10]$ whereas the late-onset disease remains stable [10]. Recently, a remarkable increase in S. agalactiae invasive infections in immunocompromised adults and the elderly has been observed. Worryingly, the estimated mortality attributable to $S$. agalactiae severe infections in the elderly is more than $50 \%[11,12]$. Another raising concern is the potential emergence of tolerance to penicillin [13], the drug of choice for prophylaxis and therapy of $S$. agalactiae infections, and the resistance to clindamycin and erythromycin which are commonly used in patients with a history of beta-lactams allergy [8].

Although the highest burden of $S$. agalactiae infections has been reported in industrialized countries, $S$. agalactiae maternal colonization and invasive infections have been also seen in non-industrialized nations [14-17]. Nevertheless, studies on the characterization and epidemiology of S. agalactiae are still limited in developing countries and implementation of control strategies remains undefined due to the lack of supporting studies [18]. Severe neonatal infections and fatal cases caused by $S$. agalactiae have been reported in Latin America [7], however the behaviour and trends of $S$. agalactiae in non-pregnant adults are unknown and somehow underestimated [7]. To better understand the behaviour of $S$. agalactiae infections in our region, we have described the epidemiological, clinical and microbiological characteristics of invasive and noninvasive $S$. agalactiae isolates from patients admitted to a tertiary care hospital in Colombia over a 17 -year period. We hypothesize that emerging trends in S. agalactiae epidemiology are similar to those from high income countries and continuous surveillance and control measures should be adopted.

\section{Methods \\ Patients}

This retrospective and cross-sectional study included clinical and microbiological records from patients with S. agalactiae isolates admitted in a tertiary care hospital at two time periods. Our hospital is a university-affiliated institution serving a population of approximately 700,000 located in Cali (western Colombia), the third most populous city in the country. This national reference hospital has capacity for 500 beds, 180 of them in intensive care unit (ICU), it also has specialized units for transplantation, cancer surgery and dialysis. The medical center and the laboratory also offer a wide range of outpatient services and community-level healthcare.

A first survey was conducted from 1994 to 2001. Information of S. agalactiae isolates was collected from the laboratory records (MicroScan, Baxter Scientific software). Invasive and noninvasive isolates were identified and clinical data from invasive infections were captured from the hospital's patient files. Following the implementation of a new laboratory system, a second study period started from 2004 to 2012 and microbiology and clinical data were obtained as for the first survey (MicroScan LabPro software program; WalkAway Baxter Scientific). During the transition between laboratory systems (2002-2003) microbiology data were not available.

\section{Isolates}

S. agalactiae isolates were identified by conventional methods based on hemolysis, colony morphology, catalase reaction and biochemical tests (Microscan WalkAway, Baxter Scientific), in some cases $(<10 \%)$ bacterial identification was confirmed using the Vitek 2XL, bioMérieux system. Antimicrobial susceptibility testing was routinely performed using standard broth microdilution (Microscan WalkAway, Baxter Scientific). The minimum inhibitory concentration (MIC) was determined for penicillin, ampicillin, clindamycin, erythromycin, tetracycline and vancomycin. From 2004 to 2012, linezolid and levofloxacin were also included for susceptibility testing. Interpretive standards published by the Clinical and Laboratory Standards Institute (CLSI) were used to categorize the MICs as susceptible, intermediate, or resistant [19]. Microbiology laboratory was enrolled in periodical internal and external quality control programs to assure accuracy.

An invasive isolate was defined as that obtained from usually sterile body sites including blood, soft tissue (abscesses, ulcers and wounds) cerebrospinal fluid and synovial, peritoneal or pleural specimens. Isolates from urine, sputum and secretions were considered noninvasive. This 
work was approved by the Ethics Committee of the Foundation Valle del Lili Hospital (Number 170-2012).

\section{Statistical analysis}

Demographic and clinical data from each patient with severe infection were obtained from clinical records in a data collection form. Live birth and adults admission figures were provided by the hospital statistics department. Univariate and multivariate analysis were conducted using Epi info version 7 (CDC). For comparison of clinical and epidemiological variables Chi square and Fisher's exact test were used as appropriate. A p value $<0.05$ was considered significant.

\section{Results}

From 1994 to 2001 a total of 201 S. agalactiae isolates were identified, 139 (69.2\%) were from outpatient samples and $62(30.8 \%)$ from inpatients samples. There were 152 women and 49 men (ratio 3.1:1). Isolates were recovered from urine $38.3 \%$, vaginal exudates $27.8 \%$, soft tissue $12.9 \%$, blood $8.5 \%$, genital male secretions $6 \%$, sterile fluids $2 \%$ and other sources $4.5 \%$.

The annual frequency of $S$. agalactiae is shown in Figure 1. An increase in the total of isolates was observed between 1996 and 1998, but no particular reasons for this were identified. In this 8-year period, $22.9 \%$ were considered S. agalactiae invasive isolates ranging from 6 to 34\%, higher prevalence rates were observed between 1998 and 2000 with $65 \%$ of the total cases occurring in this period.

Six hundred and seventy one isolates were recovered during the last 9-year period (2004 to 2012), 530 (79\%) from outpatient samples and 141 (21\%) were from hospitalized patients. From the total of 671 patients, 540 were females and 131 were males (ratio 4.1:1). Sites of isolation included: urine $47.8 \%$, vaginal exudates $32.6 \%$, soft tissue $2.7 \%$, blood $9 \%$, sterile fluids $2.5 \%$ genital male secretions $1.3 \%$ and other sources $4.1 \%$. There were considerably more $S$. agalactiae isolates in the recent years; the number of isolates increased from 82 in 2009 to 112 in 2010 (Figure 1). From 2004 to 2012, 14\% S. agalactiae isolates were classified as invasive isolates ranging from $6.8 \%$ to $23.8 \%$.

Incidence for neonatal infections for the 17-year period was 1.34 per 1000 livebirths (95\% CI: 0.85-2.0). The incidence rate for early- onset infections was 0.99 per 1000 livebirths (95\% CI $0.57-1.5$ per 1000) and the late- onset incidence was 0.35 per 1000 livebirths (95\% CI 0.16- 0.84). For non-pregnant adults, overall incidence was 0.75 severe cases per 1000 admissions (95\% CI: 0.61- 0.89).

\section{Invasive S. agalactiae infections}

Noninvasive isolates were mainly recovered from outpatient samples (84\%) and invasive isolates obtained from inpatient samples (63\%). From 1994 to 2001 a total of 46 cases of severe infections were reported, 11 (24\%) in neonates and $35(76 \%)$ in adults. Invasive isolates were recovered from soft tissue 25 (54.3\%), blood 17 (37\%) and sterile fluids 4 (8.7\%) (Figure 2A). Seventeen cases of bacteremia were observed: $11(64.7 \%)$ were in neonates (6 early- and 5 late-onset infections) and 6 $(35.3 \%)$ in adults (Figure 2B). The estimated incidence for $S$. agalactiae neonatal infections in this period was 1.7 per 1000 livebirths (95\% CI 0.86-3.0). The incidence rates for early and late-onset disease were 0.9 per 1000 livebirths (95\% CI $0.35-2.0)$ and $0.79 \times 1000$ livebirths (95\% CI 0.26-1.8) respectively. Overall mortality for neonates was $36.4 \%(4 / 11)$, all deaths occurred in patients with early-onset infections.

Soft tissue infections prevailed in non-pregnant adults $(71.4 \%, 25 / 35)$ only $28.6 \%(10 / 35)$ of the invasive isolates were recovered from blood or sterile fluids. No in-hospital deaths were reported in adults. The estimated incidence for invasive infections in non-pregnant adults was 0.79 per 1000 admissions (95\% CI 0.55-1.1).

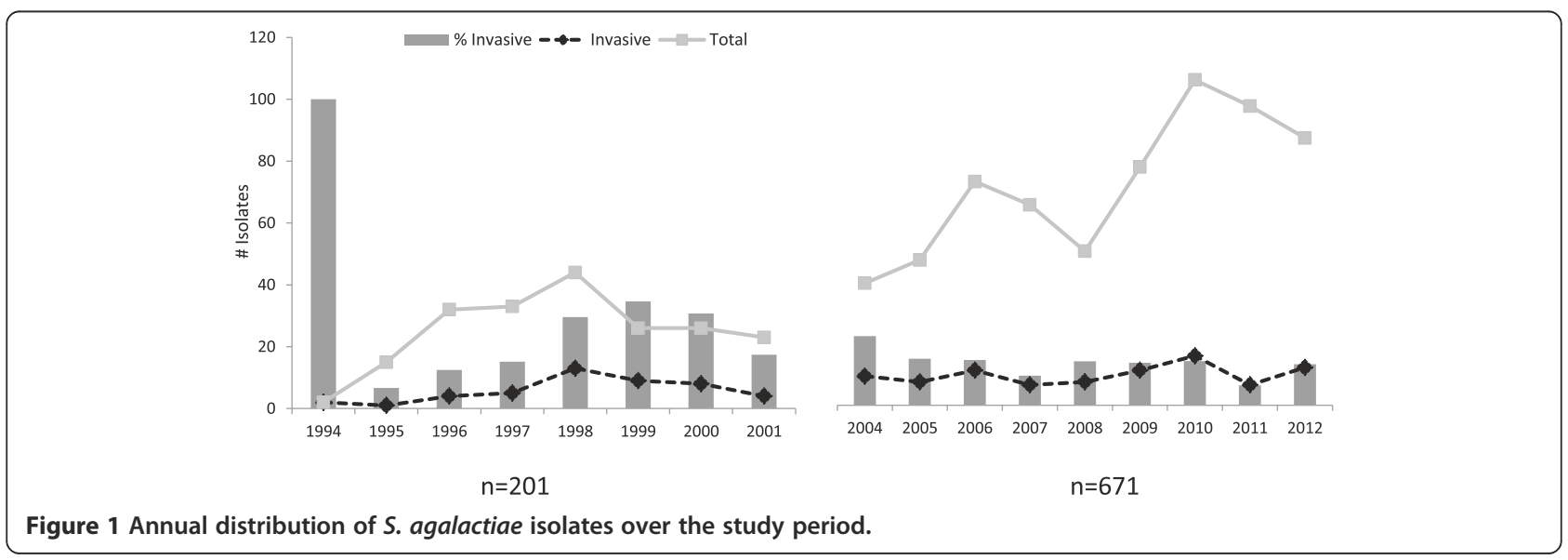



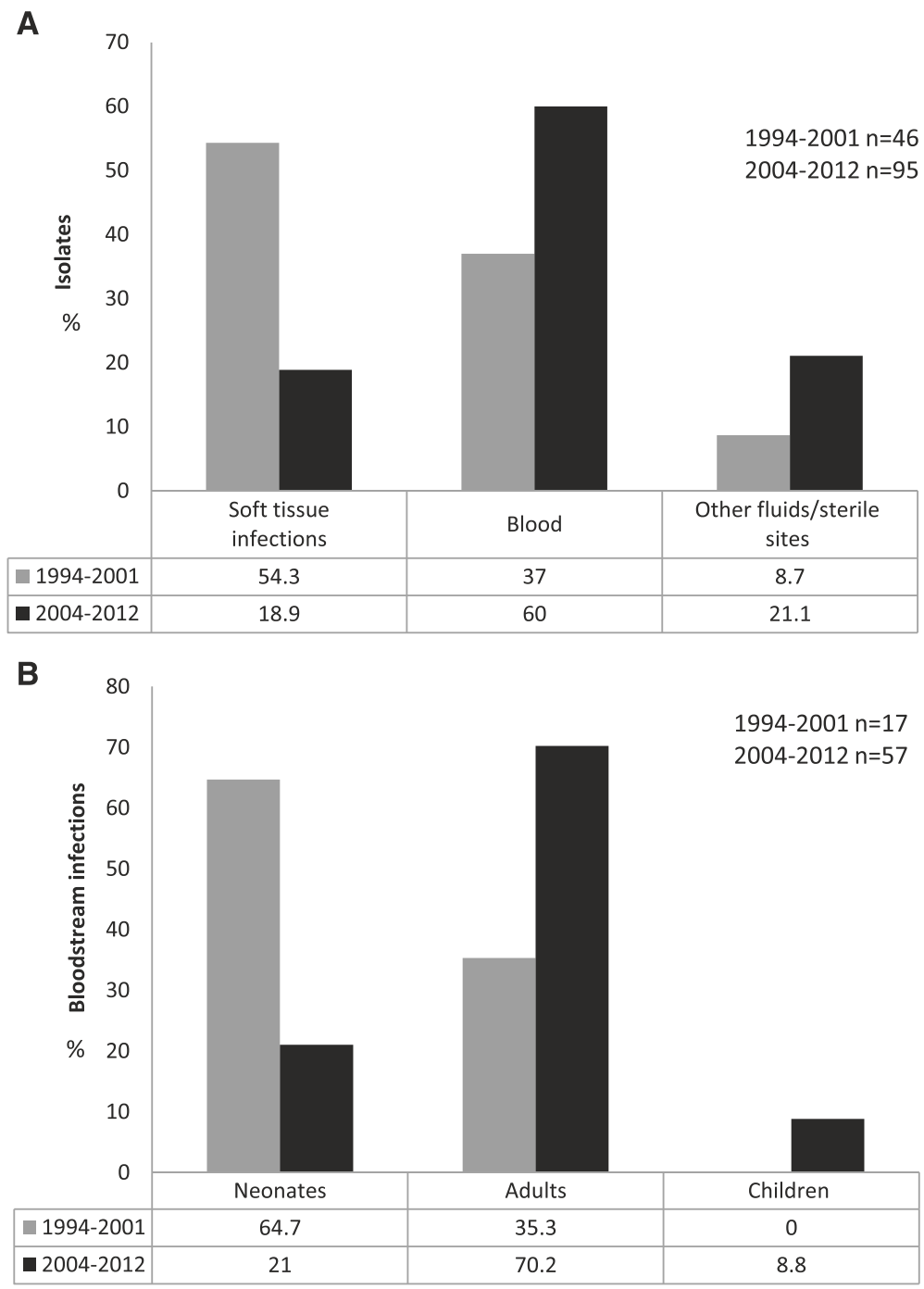

Figure 2 S. agalactiae invasive isolates in the study population. A) S. agalactiae invasive infections distributed by site of isolation, 1994-2001 and 2004-2012. B) Distribution of S. agalactiae bloodstream infections, 1994-2001 and 2004-2012.

For the second period S. agalactiae was recovered from 95 cases of severe infections, $12(12.6 \%)$ neonates, $5(5.3 \%)$ children and $78(82 \%)$ adults. Invasive isolates were obtained from blood 57 (60\%), soft tissue 18 (18.9\%), sterile fluids $17(17.9 \%)$ and $3(3.2 \%)$ catheters (Figure 2A). Fifty seven patients with bacteremia were reported: 12 (21\%) were in neonates (11 early- and one late-onset infection), 5 (8.8\%) in children and 40 (70.2\%) in adults (Figure 2B). Mortality rate for neonates was lower than that for the first period $(16.6 \%, 2 / 12)$, two neonates died; one with an early-onset infection and one with late-onset infection. Risk factors identified in early neonatal infections were chorioamnionitis (3 cases), gestational diabetes ( 1 case), prematurity (4 cases), hemolytic disease of the newborn ABO (1 case) and maternal fever (1 case). The only late onset infection was considered nosocomial. In this study period, the estimated incidence for S. agalactiae neonatal disease was 1.1 per 1000 live births (95\% CI 0.58-1.9), mostly early-onset infections (1 per 1000 livebirths), and the incidence for late- onset disease was 0.09 per 1000 livebirths (CI 95\%: 0.002-0.5).

S. agalactiae invasive infections affected five children ranging in age from 5 months to 7 seven years. All infants had underlying conditions including hepatic disorders $(3 / 5)$, cancer (1/5) and major surgical procedures $(1 / 5)$.

The estimated incidence for invasive infections in adults was 0.73 per 1000 admissions (95\% CI 0.57-0.90). Most patients with invasive S. agalactiae infections (91\%, 52/57) had at least one chronic underlying condition such as: metastatic cancer, diabetes or transplant history. Twenty of the 57 patients (35\%) had more than one underlying condition or predisposing factor (Table 1). No predisposing conditions were clearly identified in 5 cases: it was assumed that in two patients $S$. agalactiae may spread from 
Table 1 Clinical characteristics of S. agalactiae invasive infections in non-pregnant adults $2004-2012$

\begin{tabular}{|c|c|c|c|c|}
\hline & $\begin{array}{l}\text { Total Invasive infections } \\
\mathrm{n}=57 \mathrm{n}(\%)\end{array}$ & $\begin{array}{l}\text { Female } n=21 \\
\mathrm{n}(\%)\end{array}$ & $\begin{array}{l}\text { Male } n=36 \\
n(\%)\end{array}$ & $\begin{array}{l}\text { Bloodstream Infections } \\
\mathrm{n}=34 \mathrm{n}(\%)\end{array}$ \\
\hline Female & $21(36.8)$ & & & $12(35.3)$ \\
\hline Male & $36(63.2)$ & & & $22(64.7)$ \\
\hline$\geq 60$ y.o & $25(43.9)$ & $8(38)$ & $15(42)$ & $18(53)$ \\
\hline Mean & & 53 у. о. & 55 y. о. & \\
\hline Range & & [17-82] & [24-83] & \\
\hline In-hospital fatality & $10(17.5)$ & $3(14.3)$ & $6(16.7)$ & $7(20.6)$ \\
\hline Polymicrobial infections & $13(22.8)$ & $2(9.5)$ & $11(31)$ & $7(20.6)$ \\
\hline Bloodstream infections & $34(59.7)$ & $12(57.1)$ & $22(61.1)$ & \\
\hline \multicolumn{5}{|l|}{ Underlying conditions } \\
\hline Cancer & $14(24.6)$ & $8(38)$ & $6(16.7)$ & $10(29.4)$ \\
\hline -Hematologic malignancies & $7(12.3)$ & $4(19)$ & $3(8.3)$ & $5(14.7)$ \\
\hline Diabetes & $16(28)$ & $6(28.6)$ & $10(27.8)$ & $7(20.6)$ \\
\hline Transplant & $4(7)$ & - & $2(5.6)$ & $1(2.9)$ \\
\hline Cirrhosis/liver disorder & $4(7)$ & $1(4.8)$ & $3(8.3)$ & $3(8.8)$ \\
\hline Renal disorder & $7(12.3)$ & $1(4.8)$ & $2(5.6)$ & $3(8.8)$ \\
\hline Lung disease & $3(5.3)$ & $2(9.5)$ & $2(5.6)$ & $2(5.9)$ \\
\hline HIV & $3(5.3)$ & - & $3(8.3)$ & $1(2.9)$ \\
\hline Autoimmune disorder & $3(5.3)$ & $1(4.8)$ & $1(2.8)$ & $3(8.8)$ \\
\hline Other & $3(5.3)$ & $2(9.5)$ & $2(5.6)^{*}$ & $2(5.9)^{* *}$ \\
\hline More than one underlying condition & $20(35)$ & $6(28.6)$ & $14(38.9)$ & $13(38.2)$ \\
\hline \multicolumn{5}{|l|}{ Portal of entry } \\
\hline Primary bacteremia & & & & $14(41.2)$ \\
\hline Skin and soft tissue & & & & $8(23.5)$ \\
\hline Respiratory tract & & & & $7(20.6)$ \\
\hline Gastrointestinal tract & & & & $4(11.8)$ \\
\hline Urinary tract & & & & $1(2.9)$ \\
\hline
\end{tabular}

y.o: years old.

*No underlying condition was identified in 5 cases.

**No underlying condition was identified in 2 bloodstream infections.

the gastrointestinal tract to blood, one patient had an abdominal trauma before $S$. agalactiae infection and one patient had acute self-limited gastroenteritis before having S. agalactiae bacteremia. The remaining 3 patients developed S. agalactiae bone infections, one patient had septic arthritis and other patient suffered spondylodiscitis with no other associated risk factor or condition. The third patient with bone infection had morbid obesity. In none of the three patients could the primary site of dissemination be identified, $S$. agalactiae was not found in other infection sites despite being isolated from blood.

S. agalactiae invasive infections had a similar behaviour in male and female patients. However, females had two times higher percentage of cancer (38\%) than male (16.7\%) by contrast liver disorders were more frequently seen in male ( $4.8 \%$ women vs $8.3 \%$ men). Polymicrobial infections were also more frequent in male (Table 1). In non-pregnant adults, 34 bloodstream infections were documented. Bacteremia was more prevalent in male and the elderly particularly in those aged 60 or over, clinical features of these cases are described in Table 1. Interestingly, 7 (20.6\%) patients had mixed bloodstream infections. Other clinical syndromes associated with $S$. agalactiae infections were abscesses and cellulitis $8.2 \%$, arthritis $5.5 \%$ and peritonitis $5.5 \%$. In 13 cases (22.8\%) mixed infections were reported.

A total of $40(70 \%)$ patients with invasive isolates were admitted in ICU with complications mainly associated to neurological disorders and respiratory distress. Overall in-hospital mortality in non-pregnant adults was 19.2\% and $24.1 \%$ in patients with bloodstream infections, however, neither age nor bloodstream invasion of $S$. agalactiae were significantly associated with fatality $(\mathrm{p}=0.4$ and $\mathrm{p}=0.34$ respectively). 


\section{Noninvasive infections}

Over the study period a great number of isolates were obtained from urine samples. A total of 398 isolates from urine were recovered from 322 (81\%) female and 76 (19\%) male patients with a ratio 4.2:1. Semi-quantitative bacteriuria was determined in 161 patients. The mean of the counts was $75.750 \pm 27.507 \mathrm{CFU} / \mathrm{ml}$, with no statistical difference between men and women $(74.661 \pm 28.245 \mathrm{CFU} / \mathrm{ml}$ and $81.111 \pm 23.260 \mathrm{CFU} / \mathrm{ml}$ respectively). However $54 \%$ of the bacteriuria counts were $<100.000 \mathrm{CFU} / \mathrm{ml}$ and $46 \%$ were $\geq 100.000 \mathrm{CFU} / \mathrm{ml}$. Only $3.1 \%$ of the infections were polymicrobial and $96.9 \%$ were single-microorganism infections.

\section{Susceptibility}

In 1994-2001 susceptibility rates to penicillin and ampicillin were $94 \%(189 / 201)$ with MIC breakpoints $\leq 0.12$ and $\leq 0.25 \mu \mathrm{g} / \mathrm{ml}$ respectively $6 \%(12 / 201)$ of $S$. agalactiae isolates had a MIC in the 0.25 to $2 \mu \mathrm{g} / \mathrm{ml}$ range which is considered at the upper range of expected susceptibility [20]. Susceptibility rates to other antimicrobials were: 97.2\% erythromycin, $94.8 \%$ clindamycin, $21.4 \%$ tetracycline and $100 \%$ vancomycin.

From 2004 to 2012 susceptibility rates for both penicillin and ampicillin were $98.6 \%$. Higher MICs to penicillin $(\geq 0.25 \mu \mathrm{g} / \mathrm{ml})$ or ampicillin $(\geq 0.5 \mu \mathrm{g} / \mathrm{ml})$ were observed in $1.4 \%$ isolates Eight isolates showed MICs $\geq 2 \mu \mathrm{g} / \mathrm{ml}$ for ampicillin, 3 of them were recovered from sterile sites and the remaining five from genital secretions. Six isolates exhibited decreased susceptibility to penicillin; two were recovered from sterile sites. Penicillin nonsusceptible isolates showed MICs $\geq 2 \mu \mathrm{g} / \mathrm{ml}$, three of them with reduced susceptibility to ampicillin and the other three were resistant to erythromycin or tetracycline. In 2012, we found two S. agalactiae isolates showing a substantially reduced susceptibility to penicillin with MICs $>8 \mu \mathrm{g} / \mathrm{ml}$, one of them obtained from catheter, also showed reduced susceptibility to ampicillin (MIC $4 \mu \mathrm{g} / \mathrm{ml}$ ) and resistance to erythromycin (MIC $>4 \mu \mathrm{g} / \mathrm{ml}$ ). The remaining isolate recovered from urine showed decreased susceptibility to linezolid (MIC $2 \mu \mathrm{g} / \mathrm{ml}$ ). Unfortunately these strains were not saved for further testing.

Susceptibility rates to erythromycin and clindamycin were $87.5 \%$ and $90.6 \%$ respectively. A significant increase in erythromycin resistance was observed over the two study periods $(2.8 \%$ in $1994-2001$ vs $12.5 \%$ in $2004-$ $2012 \mathrm{p}=0.0001$ ). A monitoring of the resistance over 2004 to 2012 revealed an increase in erythromycin resistance since 2007 with the highest prevalence rates in 2008 and 2012 (Figure 3). Among the total isolates, 8.9\% (60/ 671 ) were only resistant to erythromycin, $2.4 \%(16 / 671)$ to clindamycin and concurrent resistance to both clindamycin and erythromycin was identified in 3.7\% (25/671). 24.8\% of the erythromycin resistant isolates showed constitutive resistance to macrolide-lincosamine-streptogramine (MLS). Susceptibility to other antibiotics was: $97.5 \%$ levofloxacin, $100 \%$ linezolid, $11.6 \%$ tetracycline and $99.7 \%$ vancomycin. Additionally $98.8 \%$ isolates had MICs $<1 \mu \mathrm{g} / \mathrm{ml}$ for daptomycin and rifampicin. No differences were observed in the susceptibility profile of invasive and noninvasive S. agalactiae only a slight decrease in the susceptibility MICs to ampicillin was observed in invasive isolates $(\mathrm{p}=0.02)($ Table 2$)$.

\section{Polymicrobial and recurrent infections}

S. agalactiae was commonly isolated with other bacteria and fungi. Invasive isolates of $S$. agalactiae were significantly involved in polymicrobial infections when compared to noninvasive isolates $[13.7 \%,(13 / 95)$ vs $3.5 \%(20 /$ 576) $\mathrm{p}=0.0002]$. In 13 polymicrobial invasive infections $S$. agalactiae was concomitantly found with Escherichia coli (4/13), Staphylococcus aureus 2/13, Klebsiella pneumoniae 1/13, Citrobacter freundii 1/13, Enterobacter aerogenes $1 / 13$, Streptococcus viridans $1 / 13$ and Candida albicans.

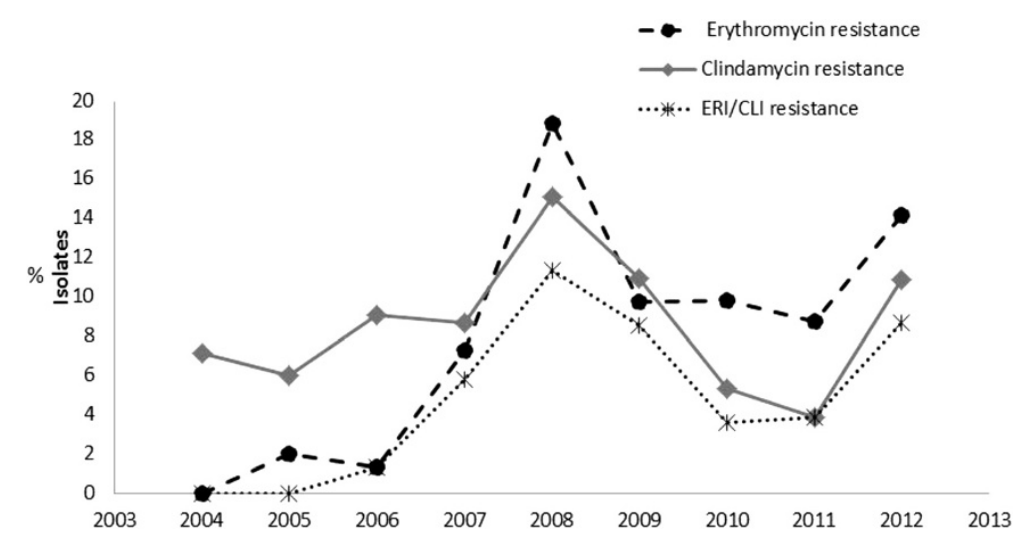

Figure 3 Erythromycin and clindamycin resistance in S. agalactiae isolates, 2004-2012. Erythromycin (ERI) resistance (dashed line) and clindamycin (CLI) resistance (grey solid line) are shown by year of isolation. Concurrent resistance to both clindamycin and erythromycin is also shown (dotted line with asterisk). 
Table 2 Antimicrobial susceptibility profiles for invasive and noninvasive $\mathbf{S}$ agalactiae isolates

\begin{tabular}{|c|c|c|c|c|}
\hline \multirow[t]{2}{*}{ Antibiotic } & \multicolumn{2}{|c|}{ 1994-2001 S. agalactiae susceptibility (\%) } & \multicolumn{2}{|c|}{ 2004-2012 S. agalactiae susceptibility (\%) } \\
\hline & Invasive & Noninvasive & Invasive & Noninvasive \\
\hline Ampicillin & 100 & 98.3 & 95.4 & 99.1 \\
\hline Penicillin & 100 & 97.5 & $96.3^{*}$ & 99 \\
\hline Clindamycin & 93 & 94.5 & 90.7 & 91.4 \\
\hline Erythromycin & 97.5 & 97 & 85.3 & 88.2 \\
\hline Levofloxacin & - & - & 96.9 & 97.6 \\
\hline Tetracycline & 21.4 & 8.1 & 9.4 & 11.9 \\
\hline Vancomycin & 100 & 100 & 100 & 99.6 \\
\hline Linezolid & - & - & 100 & 100 \\
\hline
\end{tabular}

In a total of 20 noninvasive infections and colonizations S. agalactiae was recovered with Escherichia coli 4/20, Staphylococcus aureus 5/20 and Candida albicans 5/20. Polymicrobial infections were not associated with fatality $(\mathrm{p}=0.45)$.

Recurrent isolation and/or colonization were recorded in the second period of study. A total of 36 (5.4\%) cases with at least two documented infections or S. agalactiae colonizations were seen through the 2004-2012 period. One recurrent invasive infection was reported in a $67 \mathrm{y}$. o male with prostate cancer who developed osteomyelitis and epidural abscess and received a penicillin regimen. $\mathrm{He}$ had a relapsed two years later with positive cultures; the patient was treated with ceftriaxone.

\section{Microbiology of S. agalactiae}

A total of 497 isolates were biochemically characterized. The most common biotypes comprise strains that were beta-hemolytic, resistant to bacitracin and non-carbohydrate fermenters. Non-hemolysin producing isolates emerged since 2008 and they were mostly recovered from urine samples (71\% of isolates from urine vs $29 \%$ from other samples, $\mathrm{p}=0.0001$ ). Interestingly a small percentage of $S$. agalactiae isolates showed biochemical profiles typically seen in animal strains [21]. Four isolates $(0.8 \%)$ were susceptible to bacitracin and 71 (9\%) were lactose fermenters.

\section{Therapy}

In our hospital the most common therapeutic regimen administrated in neonatal infections was the ampicillin/ gentamicin combination; however, after a $S$. agalactiae positive culture, penicillin or ampicillin treatment alone was adopted. Vancomycin was mainly used to treat S. agalactiae infections in adults $(24.5 \%, 13 / 49)$ followed by ceftriaxone $(18.4 \%, 9 / 49)$ and penicillin $(10.5 \%, 5 / 49)$. A combination therapy was administrated in many cases to cover concurrent bacterial infections or as prophylaxis to prevent them. Effective control of the underlying disease was also addressed. No bacteriological failure was documented after receiving empiric or consolidate antimicrobial regimen.

\section{Discussion}

The estimated burden of the $S$. agalactiae disease in lowand medium-income countries remains to be determined. A recent meta-analysis estimated the global incidence of S. agalactiae neonatal infections to be 0.53 per 1000 livebirths with $9.6 \%$ mean case-fatality ratio [7], however few studies from low income countries were included and only one from Latin America. We have reported the incidence, epidemiology and emerging trends of S. agalactiae infections in our hospital over 17 years. Overall incidence of neonatal infections was 1.34 per 1000 livebirths which is 2.5 times higher than the estimated global incidence and twice higher the incidence reported for the Americas (0.67 per 1000 livebirths) [7]. Data reported from Latin América are variable and fluctuate between $0.3-1.15 \times 1000$ livebirths, with mortality rates ranging from 20 to $60 \%$ [5,9,22-27]. Neonatal incidence reported here is lower than previous reports by Bajaras et al. in Colombia [23] (neonatal incidence: 1.8 per 1000 livebirths) and similar to that reported from Brazil by Miura et al. (1.15 per 1000 livebirths 95\% CI: 0.7-1.9) [24], possibly due to similar hospital characteristics. By contrast, lower mean incidence of neonatal infections has been reported by Sarubbi et al. in Argentina (0.9 per 1000 livebirths) [25], Guzmán et. al. in Chile (0.73 per 1000 livebirths) [9], Vaciloto et al. in Brazil [0.63 $\times 1000$ livebirths (95\% CI 0.13-1.85)] [26] and Solorzano in Mexico [0.65 × 1000 livebirths (95\% CI 0.38- 1.11)] [27]. In this study we have seen a decline in the $S$. agalactiae neonatal incidence from $1.7 \times 1000$ livebirths in 19942001 to 1.1 per 1000 livebirths $(\mathrm{p}=0.29)$ in $2004-2012$. Early-onset disease remained stable whereas a substantial decreased in late-onset disease was observed. However, our data may represent even a higher incidence as it has been suggested that a real S. agalactiae neonatal incidence 
may be two or three times higher than that defined by microbiological confirmation [28].

Averaged mortality caused by neonatal infections in the 17 -year period (26\%) was also higher than the global case fatality ratio (9.6\%) [7], nevertheless in the last 9 years a reduction in the number of fatal cases from $36.3 \%$ to $16.6 \%$ was observed, probably due to the recognition of the disease and early treatment. Similarly to previous studies, most fatalities occurred in early-onset infections and low-birth-weight infants [7].

Worldwide incidence of invasive infections in nonpregnant adults is widely variable and influenced by the population of individuals with predisposing factors. In high income countries a 2-4 fold increase in $S$. agalactiae severe infections has been recorded since 1990 [29]. Incidence of invasive infections in adults ranges from 3.4 to $7 \times 100.000$ in US, and from 0.3 to $0.96 \times 1000$ admissions in Europe [30]. In our study the behaviour and incidence of the $S$. agalactiae invasive in adults $(0.75 \times$ 1000 admissions) seems to be similar to that reported in high income countries. We observed that in 1994-2001 most of the bacteremias caused by $S$. agalactiae occurred in neonates (11/17, 64.7\%), whereas in 2004-2012 these infections prevailed in adults $(21.1 \%$ vs $70.1 \%, \mathrm{p}=0.002)$. Interestingly, $S$. agalactiae also emerged in non-infant children with predisposing conditions $(0.75 \%)$. This situation is consistent with reports from other parts of the world where $S$. agalactiae infections in adults account for $75 \%$ of S. agalactiae invasive disease [20] and cases in non-infant children are rising [31].

Most $S$. agalactiae invasive infections and particularly S. agalactiae bacteremia occurred in old aged patients but in contrast with other studies [32,33] males were the most affected. Skin and soft tissue were the main portals of entry for $S$. agalactiae blood invasion; however in most cases the source infections could not be identified. The most prevalent risk factors identified in non-pregnant adults with severe $S$. agalactiae infections were diabetes and cancer, particularly cancer of the immune system. Interestingly we reported three cases of $S$. agalactiae bone infections, formerly considered unusual, in patients with no obvious underlying conditions.

Worldwide, the overall in-hospital mortality for nonpregnant adults ranges from $3-47 \%$. In our study severe clinical consequences during the $S$. agalactiae infection far exceed previous reports (70\% here vs 19\%) [4]. A total of $19 \%$ patients with predisposing conditions and concurrent $S$. agalactiae invasive infection died. These findings are similar to those reported in Thailand, US and Taiwan with mortality rates ranging from $14 \%$ to $19 \%$ $[12,33]$. As for other studies, mortality in non-pregnant adults over the two study periods had a substantial increase ( $0 \%$ vs $19.2 \%, \mathrm{p}=0.01)$ whereas neonatal mortality seems to decrease over time.
S. agalactiae isolates were consistently obtained from urine, vaginal swabs, blood and soft tissues. Over the study period a steady increase on the total of $S$ agalactiae isolates was recorded, particularly in noninvasive isolates from urine $(\mathrm{p}=0.02)$ supporting the emergence of $S$. agalactiae in urinary tract infections in our region. Similar to other studies, most urine isolates were obtained from women and $>50 \%$ of the counts were $<10^{5}$ $\mathrm{CFU} / \mathrm{ml}$, this agrees with the suggestion that $S$. agalactiae bacteruria should be interpreted by lowering the commonly used cut off values of $\geq 10^{5} \mathrm{CFU} / \mathrm{ml}$ [34].

A changing trend was also seen in S. agalactiae invasive isolates. Soft tissue isolates declined over the last study period $(p<0.0001)$. A substantial shift form subcutaneous to bloodstream infections in non-pregnant adults was observed $(60 \%, \mathrm{p}=0.01)$, this was even higher than that reported in similar studies (23-36\%) [12].

Previous studies have found that important proportion of S. agalactiae infections are nosocomial (22\%-26\% [33,35]) and polymicrobial (26\%) [35]. Studies in non-pregnant adults by Skoff and Chen-Mao found 6.3 and $8.9 \%$ of polymicrobial bacteremia, $S$. aureus was the concurrent bacteria in half cases $[29,33]$. Here we reported a lower overall rate of polymicrobial infections $(16.8 \%)$ however the frequency of polymicrobial bacteremia in our population was higher compared with other studies. It was also seen that Enterobacteriaceae and other gram negative bacteria rather than $S$. aureus were co-cultured with $S$ agalactiae, we assume they have been co-transferred from an endogenous source such as gastrointestinal or urinary tract. Invasive isolates were significantly more involved in polymicrobial infections.

It has been assumed that many problems regarding diagnosis and detection persist in developing countries leading to an underestimation of the $S$. agalactiae burden. In this study we also described the biochemical characteristics of $S$. agalactiae isolates in our region. The presence of non-hemolysin or low-hemolysin producing isolates may have diagnosis implications. One of the leading tests for $S$. agalactiae identification is based on its hemolytic properties and low-hemolysin producers may not be detected unless differential media are used [36]. Nonhemolysin producing isolates were frequently recovered from urine samples and blood agar was used to verify hemolysis in these isolates. Although this phenotype may reflect an intrinsic characteristic of urine isolates in this study, it is also possible that urine differential culture media may induce hemolysin inhibition; however, this will need further investigation.

$S$ agalactiae phenotypes from animal origin have been previously identified in humans [37]. In a small percentage of our isolates we identified phenotypic traits described in bovine $S$. agalactiae isolates such as lactose fermentation, lack of hemolysin and susceptibility to bacitracin [21]. 
Furthermore, most S. agalactiae isolates with higher MICs for penicillin were also lactose fermenters. However any association between animal and human S. agalactiae isolates and resistance needs to be further elucidated.

S. agalactiae has been universally susceptible to penicillin and other beta lactams. One consequence of the implementation of chemoprophylaxis in industrialized countries is the increasing reports of $S$. agalactiae resistance to macrolide-lincosamide-streptogramine antibiotics and the emergence of penicillin-nonsusceptible isolates. Although in many developing countries the $S$. agalactiae prophylaxis is not widely used, macrolide and lincosamine resistance is also rising. All over the world resistance to erythromycin has been also attributed to therapy for other microorganisms [38].

In high-income countries resistance rates to erythromycin range from 3 to $54 \%$ and 1 to $43 \%$ for clindamycin [39] whereas studies in South America show resistance rates between 6 and 11\% for erythromycin and around 5\% for clindamycin $[40,41]$. In this study $S$. agalactiae isolates examined in 2004-2012 showed a significant increase in erythromycin resistance compared to those in 1994-2001 (Figure 3) however the increase in clindamycin resistance did not reach statistically significance. These resistance rates were similar to that reported by Nakamura et. al. [41]. Here, invasive and noninvasive isolates had similar susceptibility profiles which agree with erythromycin rates reported by Garland et al. [39], but contrast with studies in Brazil showing higher resistance to erythromycin in colonizing isolates [42]. Although resistance mechanisms were not determined in this study, we could identified that $24.6 \%$ of the erythromycin resistant isolates were also resistant to clindamycin suggesting a MLS constitutive resistance phenotype, this is somewhat lower than other studies in South America and worldwide reporting up to $50 \%$ [39]. Resistance to tetracycline was a common feature (up to $88 \%$ ) as seen elsewhere (46-91\%) [38,39,41,43].

Fluoroquinolone resistance may be also present in $S$. agalactiae examined in this study as we found 7 isolates with MIC $>4 \mu \mathrm{g} / \mathrm{ml}$ for levofloxacin. Levofloxacinresistant isolates have been reported since 2010 in Argentina [44] and Brazil [41].

So far, resistance to penicillin or ampicillin remains to be defined by the CLSI, although controversial [20], in vitro S. agalactiae penicillin nonsusceptibility (MIC $>0.25 \mu \mathrm{g} / \mathrm{ml}$ ) has been documented since 1995 $[13,45]$. Studies by Kimura have shown that nonsusceptible S. agalactiae (NSGBS) are mostly recovered from nonsterile body sites, they also suggest screening for NSGBS using ceftizoxime [13]. In our study, most S. agalactiae isolates remained highly susceptible to penicillin and ampicillin, however for first time in our region we describe strains with presumptive reduced susceptibility to ampicillin and penicillin (MICs $>2 \mu \mathrm{g} / \mathrm{ml}$ ). Of these, two strains exhibited MIC $>8 \mu \mathrm{g} / \mathrm{ml}$ for penicillin which is considered extremely rare. Half isolates with MICs $>2 \mu \mathrm{g} / \mathrm{ml}$ for penicillin showed resistance to erythromycin, which agrees with observations by Kimura [46] who found that NSGBS are significantly more resistance to erythromycin than penicillin susceptible isolates. In this work, we also found NSGBS in specimens from sterile sites (3/9), possibly for an endogenous nonsterile source.

Longtin et. al. have shown that NSGBS can be induced after long-term penicillin therapy. In the same study higher MICs to penicillin were associated with point mutations in specific penicillin binding proteins such as PBP 1a, PBP 2a and PBP 2x [45]. Although the development of resistance mechanisms in S. agalactiae are still under study, it is possible that susceptible adult population exposed to concomitant antibiotic penicillin or beta lactams-based therapies may be at risk of harbouring penicillin-nonsusceptible $S$. agalactiae strains.

Nevertheless, penicillin remains as the choice for the therapy of S. agalactiae infections. In this study vancomycin and ceftriaxone were usually administrated to cover other concurrent infections and complications in immunocompromised patients. In severe infections prolonged therapy was implemented to fully eradicate the pathogen and avoid persistence and recurrence. None of the patients reported microbiological failure suggesting a role for the immune system status and pathogen interactions in cases with clinical adverse outcome.

One limitation of this study is that only isolates from one medical centre were included, in addition NSGBS could not be confirmed by molecular methods due to the retrospective nature of the analysis. However, we think that our findings may represent the epidemiology in our region and the data may be compared with studies in similar hospitals in other countries.

\section{Conclusions}

One of the goals for the millennium is to decrease the mortality of children under 5 years old. In our country, neonatal mortality represents $63 \%$ of the children fatalities, $43 \%$ occurring in the first week of life [47], however the impact of $S$. agalactiae on these figures is still unknown. We have shown that $S$. agalactiae infections may behave in a similar manner to those reported in high and middle income countries. This study has revealed a high incidence and lethality of early neonatal infections, emergence of severe infections in non-pregnant adults and an increase of bloodstream and urinary tract infections. All these data together with the emergence of antimicrobial resistance and tolerance, strongly support the implementation of prevention measures. We have also identified non-infant children with underlying conditions as a population at risk for invasive infections. 
The epidemiology of S. agalactiae varies geographically and population at risk must be identified and monitored. Routinely risk-based or S. agalactiae swab screening in pregnant women, chemoprophylaxis and/or effective vaccine strategies should be considered in high risk population. Tertiary care hospitals in Latin America having transplantation, dialysis, cancer units or immunocompromised patients should recognize S. agalactiae as a severe cause of disease by monitoring and implementing policies to improve routinely detection, susceptibility testing and control. In these settings susceptibility to penicillin, clindamycin and erythromycin should be tested particularly in immunosuppressed patients at high nosocomial risk and/or those highly exposed to antibiotic therapy. Penicillin-nonsusceptible strains or isolates with a MIC range near the susceptibility breakpoint $(>0.12 \mu \mathrm{g} / \mathrm{ml})$ should be confirmed and further investigated to examine the potential molecular mechanism involved.

S. agalactiae vaccination strategies might be an effective approach to overcome $S$. agalactiae emergence and contribute to reduce the burden of $S$. agalactiae infection in the developing world. However, studies on serotype distribution, resistance mechanisms and virulence factors urge to determine its applicability in our region.

\section{Abbreviations \\ GBS: Group B Streptococcus; MIC: Minimum inhibitory concentration; \\ CLI: Clindamycin; ERI: Erythromycin; NSGBS: Nonsusceptible GBS; \\ PBP: Penicillin binding protein.}

\section{Competing interests}

The authors declare that they have no competing interests.

\section{Authors' contributions}

MPC conceived and designed the study and drafted the manuscript. CRC and MR participated in the collecting and data analysis. JDV participated in analysis of clinical data. All authors read and approved the final manuscript.

\section{Authors' information}

Maria del Pilar Crespo-Ortiz, MSc, PhD; Claudia Rocío Castañeda, MSc; Mónica Recalde BSc, Juan Diego Vélez, MD.Infectious diseases specialist.

\section{Acknowledgements}

We acknowledge Yesid Rendón and the staff at the Microbiology laboratory in Foundation Valle del Lili Hospital for technical assistance.

\section{Author details}

${ }^{1}$ Department of Biomedical Sciences, Santiago de Cali University, Cali, Colombia. ${ }^{2}$ Department of Microbiology, University of Valle, Cali, Colombia. ${ }^{3}$ Microbiology and Infectious Diseases Division, Foundation Valle del Lili Hospital, Cali, Colombia. ${ }^{4}$ Bacteriology School, University of Valle, Cali, Colombia.

Received: 23 March 2014 Accepted: 22 July 2014

Published: 3 August 2014

\section{References}

1. Franciosi RA, Knostman JD, Zimmerman RA: Group B streptococcal neonatal and infant infections. J Pediatr 1973, 82(4):707-718.

2. Ippolito D, James W, Tinnemore D, Huang R, Dehart M, Williams J, Wingerd M, Demons S: Group B streptococcus serotype prevalence in reproductive-age women at a tertiary care military medical center relative to global serotype distribution. BMC Infect Dis 2010, 10(1):336.
3. Bliss SJ, Manning SD, Tallman P, Baker CJ, Pearlman MD, Marrs CF, Foxman B: Group B Streptococcus colonization in male and non-pregnant female university students: a cross-sectional prevalence study. Clin Infect Dis 2002, 34(2):184-190.

4. Sunkara B, Bheemreddy S, Lorber B, Lephart PR, Hayakawa K, Sobel JD, Kaye KS, Marchaim D: Group B Streptococcus infections in non-pregnant adults: the role immunosuppression. Infect Dis 2012, 16(3):e182-e186.

5. Dagnew AF, Cunnington MC, Dube Q, Edwards MS, French N, Heyderman RS, Madhi SA, Clemens SAC: Variation in reported neonatal Group B Streptococcal disease incidence in developing countries. Clin Infect Dis 2012, 55(1):91-102.

6. Doran KS, Nizet V: Molecular pathogenesis of neonatal group B streptococcal infection: no longer in its infancy. Mol Microbio/ 2004, 54(1):23-31.

7. Edmond KM, Kortsalioudaki C, Scott S, Schrag SJ, Zaidi AKM, Cousens S, Heath PT: Group B streptococcal disease in infants aged younger than 3 months: systematic review and meta-analysis. Lancet 2012, 379(9815):547-556.

8. Verani JR ML, Schrag SJ: Prevention of perinatal group B streptococcal disease: revised guidelines from CDC. MMWR Recomm Rep 2010, 59(RR-10):1-23.

9. Guzmán DAM, Abarzua CF, Belmar JC, García CP: Resultados de la aplicación del protocolo basado en screening para la búsqueda de Streptococcus agalactiae en el tercer trimestre del embarazo: Posible impacto sobre la sepsis neonatal precoz por este agente. Rev Med Infectol 2001, 18:187-192.

10. Stoll B, Hansen NI, Sánchez P, Faix RG, Poindexter BB, Van Meurs KP, Bizzarro MJ, Goldberg RN, Frantz ID III, Hale EC, Shankaran S, Kennedy K, Carlo WA, Watterberg KL, Bell EF, Walsh MC, Schiblert K, Laptook AR, Shane AL, Schrag SJ, Das A, Higgins RD: Early onset neonatal sepsis: the burden of group B streptococcal and E. Coli disease continues. Pediatrics 2011, 127(5):817-826.

11. High KP, Edwards MS, Baker CJ: Group B streptococcal infections in elderly adults. Clin Infect Dis 2005, 41(6):839-847.

12. Chaiwarith $R$, Jullaket $W$, Bunchoo M, Nuntachit N, Sirisanthana $T$, Supparatpinyo K: Streptococcus agalactiae in adults at chiang mai university hospital: a retrospective study. BMC Infect Dis 2011, 11(1):149.

13. Kimura K, Nagano N, Nagano Y, Suzuki S, Wachino J-i, Shibayama K, Arakawa $Y$ : High frequency of fluoroquinolone- and macrolide-resistant streptococci among clinically isolated group B streptococci with reduced penicillin susceptibility. J Am Chem Soc 2013, 68(3):539-542.

14. Sad Larcher J, Capellino F, De Giusto R, Travella C, Gómez Balangione F, Kreiker G, Prats Cardona H, Zárate A, Vilaro M, Hernández D, Ruiz Orrico G: Colonización por Estreptococo beta hemolítico del grupo b durante el embarazo y prevención de enfermedad neonatal. Medicina (B Aires) 2005, 65:201-206.

15. Hernandez Maria SD: Elevada prevalencia de colonización por Streptococcus del grupo B en mujeres mexicanas embarazadas. Ginecol Obstet Mex 2006, 74:139-143.

16. Rivas C, Tallac I, Etchenique A: Colonización vaginorrectal por Streptococcus del grupo B en mujeres embarazadas, entre las 35 a 37 semanas de gestación. RMU 2006, 22:191-196.

17. Mavenyengwa RT, Afset JE, Schei B, Berg S, Caspersen T, Bergseng H, Moyo SR: Group B Streptococcus colonization during pregnancy and maternal-fetal transmission in Zimbabwe. Acta Obstet Gynecol Scand 2010, 89(2):250-255.

18. Johri AK, Lata H, Yadav P, Dua M, Yang Y, Xu X, Homma A, Barocchi MA, Bottomley MJ, Saul A, Klugman KP, Black S: Epidemiology of Group B Streptococcus in developing countries. Vaccine 2013, 31, Supplement 4(0):D43-D45.

19. CLSI: Performance Standards for Antimicrobial Susceptibility Testing; Twenty-Third Informational Supplement. In CLSI Document M100-S23. Wayne, PA: Clinical and Laboratory Standards Institute; 2013.

20. Edwards MS: Issues of antimicrobial resistance in group B Streptococcus in the Era of intrapartum antibiotic prophylaxis. Semin Pediatr Infect Dis 2006, 17(3):149-152.

21. Duarte RS, Miranda OP, Bellei BC, Brito MAVP, Teixeira LM: Phenotypic and molecular characteristics of Streptococcus agalactiae Isolates recovered from milk of dairy cows in Brazil. J Clin Microbiol 2004, 42(9):4214-4222.

22. Fiolo K, Zanardi CE, Salvadego M, Bertuzzo CS, Amaral E, Calil R, Levy CE: Taxa de infecção e sorotipos de Streptococcus agalactiae em amostras 
de recém-nascidos infectados na cidade de Campinas (SP), Brasil. Rev Bras Ginecol Obstet 2012, 34(12):544-549.

23. Barajas N, Báez M: Enfermedad neonatal temprana por Streptococcus agalactiae en una unidad de recién nacidos, factores de riesgo materno-fetales asociados a severidad y mortalidad. Rev Cien Salud 2011 9(3):251-258. 251.

24. Miura E, Martin MC: Group B streptococcal neonatal infections in Rio Grande do Sul, Brazil. Rev Inst Med Trop Sao Paulo 2001, 43:243-246.

25. Sarubbi MA, Dinerstein NA, Paganini H, Botto L, Larguía MA: Bacteriemias neonatales por Estreptococo b hemolítico del grupo B: trece años experiencia. Revista Hosp Mat Inf Ramón Sarda 2000, 19(2):52-59.

26. Vaciloto E, Richtmann R, Costa HPF, Kusano EJU, Almeida MFB, Amaro ER: A survey of the incidence of neonatal sepsis by group B Streptococcus during a decade in a Brazilian maternity hospital. Braz J Infect Dis 2002, 6:55-62.

27. Solorzano-Santos F, Arredondo-Garcia J, Ortiz-lbarra F, Diaz-Ramos R, Cazares-Ortiz M, Echaniz-Aviles G: Streptococcus group B in the etiology of neonatal infection]. Bol Epidemiol (Mex City Mex) 1990, 47(3):146.

28. Bedford Russell AR, Breathnach A, Sender P: Confirmed group B streptococcus infection: the tip of the iceberg. Arch Dis Child Fetal Neonatal Ed 2001, 84(2):F140.

29. Skoff TH, Farley MM, Petit S, Craig AS, Schaffner W, Gershman K, Harrison LH, Lynfield R, Mohle-Boetani J, Zansky S, Albanese BA, Stefonek K, Zell ER, Jackson D, Thompson T, Schrag S: Increasing burden of invasive group B streptococcal disease in non-pregnant adults, 1990-2007. Clin Infect Dis 2009, 49(1):85-92.

30. Sendi P, Johansson L, Norrby-Teglund A: Invasive group B streptococcal disease in Non-pregnant adults. Infection 2008, 36(2):100-111.

31. Wu C, Wang S, Ko W, Wu J, Yang Y, Liu C: Group B streptococcal infections in children in a tertiary care hospital in southern Taiwan. J Microbiol Immunol Infect 2004, 37(3):169.

32. Tyrrell GJ, Senzilet LD, Spika JS, Kertesz DA, Alagaratnam M, Lovgren M, Talbot JA: Invasive disease Due to group B streptococcal infection in adults: results from a Canadian, population-based, active laboratory surveillance study-1996. J Infect Dis 2000, 182(1):168-173.

33. Ho C, Chi C, Ho M, Chen C, Liao W, Liu Y, Lin P, Wang J: Clinical characteristics of group B Streptococcus bacteremia in non-pregnant adults. J Microbiol Immunol Infect 2006, 39(5):396.

34. Tan C, Ulett K, Steele M, Benjamin W, Ulett G: Prognostic value of semiquantitative bacteruria counts in the diagnosis of group $B$ streptococcus urinary tract infection: a 4-year retrospective study in adult patients. BMC Infect Dis 2012, 12(1):273

35. Jackson LA, Hilsdon R, Farley MM, Harrison LH, Reingold AL, Plikaytis BD, Wenger JD, Schuchat A: Risk factors for Group B Streptococcal disease in adults. Ann Intern Med 1995, 123(6):415-420.

36. Savini V, Marrollo R, D'Antonio M, D'Amario C, Fazii P, D'Antonio D: Streptococcus agalactiae vaginitis: nonhemolytic variant on the Liofilchem ${ }^{\circledast}$ Chromatic StreptoB. Int J Clin Exp Pathol 2013, 6(8):1693.

37. Delannoy C, Crumlish M, Fontaine M, Pollock J, Foster G, Dagleish M Turnbull J, Zadoks R: Human Streptococcus agalactiae strains in aquatic mammals and fish. BMC Microbiol 2013, 13(1):41

38. Lambiase A, Del Pezzo M, Quaglia F, Testa A, Rossano F, Martinelli P, Catania MR: In vitro resistance to macrolides and clindamycin by Group B Streptococcus isolated from pregnant and non-pregnant Women. Infect Dis Obstet Gynecol 2012, 2012:5.

39. Garland SM, Cottrill E, Markowski L, Pearce C, Clifford V, Ndisang D, Kelly N, Daley $\mathrm{AJ}$, Group ftAGFAR-GRS: Antimicrobial resistance in group $B$ streptococcus: the Australian experience. J Med Microbio/ 2011, 60(2):230-235.

40. Pérez J, Limansky A, Toresani I, Ebner G, Di Bartolomeo S, De Inocenti I, Pretto G, Salazar N, Laferrara M, Bottiglieri M, Ballester D, Morales M, Rivera L, Cacace ML, Castro H, Roldán L, Notario R, Borda N, Cera G, Spoletti MJ, Gregorini E, Sutich EG: Distribución de tipo capsular y sensibilidad antimicrobiana de Streptococcus agalactiae productores de infecciones en Argentina. Rev Argent Microbiol 2004, 36:63-67.

41. Nakamura PA, Schuab RBB, Neves FP, Pereira CF, Paula GR, Barros RR: Antimicrobial resistance profiles and genetic characterisation of macrolide resistant isolates of Streptococcus agalactiae. Mem Inst Oswaldo Cruz 2011, 106:119-122.

42. Borchardt S, DeBusscher J, Tallman P, Manning S, Marrs C, Kurzynski T, Foxman B: Frequency of antimicrobial resistance among invasive and colonizing Group B Streptococcal isolates. BMC Infect Dis 2006, 6(1):57.
43. Sadowy E, Matynia B, Hryniewicz W: Population structure, virulence factors and resistance determinants of invasive, non-invasive and colonizing Streptococcus agalactiae in Poland. J Am Chem Soc 2010, 65(9):1907-1914.

44. Faccone D, Guerrero L, Méndez E, Errecalde L, Cano H, Yoya N, Togneri A, Romanowski V, Galas M, Whonet R: Fluoroquinolone-resistant Streptococcus agalactiae isolates from Argentina. Rev Argent Microbiol 2010, 3:203-207.

45. Longtin J, Vermeiren C, Shahinas D, Tamber GS, McGeer A, Low DE, Katz K, Pillai DR: Novel mutations in a patient isolate of Streptococcus agalactiae with reduced penicillin susceptibility emerging after long-term oral suppressive therapy. Antimicrob Agents Chemother 2011, 55(6):2983-2985.

46. Kimura K, Suzuki S, Wachino J-i, Kurokawa H, Yamane K, Shibata N, Nagano $\mathrm{N}$, Kato H, Shibayama K, Arakawa Y: First molecular characterization of Group B Streptococci with reduced penicillin susceptibility. Antimicrob Agents Chemother 2008, 52(8):2890-2897.

47. Planeación. DNd: "Prosperidad Para Todos". Plan de Desarrollo Nacional 2010-2014. 2010. https://sinergia.dnp.gov.co/SISMEG/Archivos/PND20102014\%20Tomo\%20l\%20CD.pdf.

doi:10.1186/1471-2334-14-428

Cite this article as: Crespo-Ortiz et al:: Emerging trends in invasive and noninvasive isolates of Streptococcus agalactiae in a Latin American hospital: a 17-year study. BMC Infectious Diseases 2014 14:428.

\section{Submit your next manuscript to BioMed Central and take full advantage of:}

- Convenient online submission

- Thorough peer review

- No space constraints or color figure charges

- Immediate publication on acceptance

- Inclusion in PubMed, CAS, Scopus and Google Scholar

- Research which is freely available for redistribution 